\title{
The Influence of Gene-Gene and Gene-Environment Interactions on the Risk of Asbestosis
}

\author{
A. Franko, ${ }^{1}$ V. Dolžan, ${ }^{2}$ N. Arnerić, ${ }^{1}$ and M. Dodič-Fikfak ${ }^{1}$ \\ ${ }^{1}$ Clinical Institute of Occupational Medicine, University Medical Centre, Ljubljana, Poljanski nasip 58, 1000 Ljubljana, Slovenia \\ ${ }^{2}$ Pharmacogenetics Laboratory, Institute of Biochemistry, Faculty of Medicine, University of Ljubljana, 1000 Ljubljana, Slovenia \\ Correspondence should be addressed to M. Dodič-Fikfak; metoda.dodic-fikfak@guest.arnes.si
}

Received 16 April 2013; Revised 3 July 2013; Accepted 3 July 2013

Academic Editor: Surinder K. Jindal

Copyright (C) 2013 A. Franko et al. This is an open access article distributed under the Creative Commons Attribution License, which permits unrestricted use, distribution, and reproduction in any medium, provided the original work is properly cited.

\begin{abstract}
This study investigated the influence of gene-gene and gene-environment interactions on the risk of developing asbestosis. The study comprised 262 cases with asbestosis and 265 controls with no asbestos-related disease previously studied for $M n S O D, E C S O D$, CAT, GSTT1, GSTM1, GSTP1, and iNOS polymorphisms. Data on cumulative asbestos and smoking were available for all subjects. To assess gene-gene and gene-environmental interactions, logistic regression was used. The associations between $M n S O D$ Ala $-9 \mathrm{Val}$ polymorphism and the risk of asbestosis and between $i N O S$ genotypes and asbestosis were modified by CAT $-262 \mathrm{C}>$ T polymorphism $(P=0.038 ; P=0.031)$. A strong interaction was found between GSTM1-null polymorphism and smoking $(P=0.007)$, iNOS $(\mathrm{CCTTT})_{n}$ polymorphism and smoking $(P=0.054)$, and between $i N O S(\mathrm{CCTTT})_{n}$ polymorphism and cumulative asbestos exposure $(P=0.037)$. The findings of this study suggest that the interactions between different genotypes, genotypes and smoking, and between genotypes and asbestos exposure have an important influence on the development of asbestosis and should be seriously considered in future research on occupational/environmental asbestos-related diseases.
\end{abstract}

\section{Introduction}

The findings of the studies indicate that, in addition to asbestos exposure, the genetic factors may influence the development of asbestosis [1-8].

The reactive oxygen and nitric species (ROS and RNS) such as superoxide anion $\left(\mathrm{O}_{2}{ }^{--}\right)$, hydrogen peroxide $\left(\mathrm{H}_{2} \mathrm{O}_{2}\right)$, hydroxyl radical $\left(\mathrm{OH}^{*}\right)$, and nitric oxide $(\mathrm{NO})$ are suggested to be involved in the pathogenesis of this disease [9-11]. Several specific enzyme systems contribute to the disposition of ROS and RNS. Superoxide dismutases (SODs) like manganese SOD (MnSOD) and extracellular SOD (ECSOD) and catalase (CAT) together with glutathione peroxidases represent an important line of the primary enzyme defence system against ROS. Superoxide dismutases catalyse the dismutation of $\mathrm{O}_{2}{ }^{--}$to $\mathrm{H}_{2} \mathrm{O}_{2}$ and oxygen $\left(\mathrm{O}_{2}\right)$, whereas CAT subsequently catalyses the conversion of $\mathrm{H}_{2} \mathrm{O}_{2}$ to water $\left(\mathrm{H}_{2} \mathrm{O}\right)$ and $\mathrm{O}_{2}[10,12,13]$. Other important enzymes involved in the detoxification of ROS and RNS are glutathione Stransferases (GSTs) such as GSTM1, GSTT1, and GSTP1 which catalyse the conjugation of reduced glutathione to different electrophiles [14-16]. The asbestos fibres have also been shown to upregulate the activity of inducible nitric oxide synthase (iNOS) and thus the production of NO by alveolar macrophages and pulmonary epithelial cells, which may play an important role in the initiation and progression of asbestosis $[11,17,18]$.

The genes coding for all these enzymes are polymorphic $[1-3,12,16,19-21]$. The most common single-nucleotide polymorphism (SNP) of the MnSOD gene results in alanine (Ala) to valine (Val) substitution (Ala-9Val); of the ECSOD gene results in arginine (Arg) to glycine (Gly) change (Arg213Gly); and of the CAT gene results in cytosine (C) to thymine $(\mathrm{T})$ substitution $(-262 \mathrm{C}>\mathrm{T})[12,13,22]$. The GSTM1 and GSTT1 genes exhibit null polymorphism due to gene deletion $[3,16]$. In the GSTP1 gene, two functional SNPs cause isoleucine (Ile) to Val substitution (Ile105Val) and Ala to Val change (Alal14Val) $[16,20]$. Based on the presence of polymorphisms in both codons (105 and 114), GSTP1 genotypes may be combined into groups with a presumed high, intermediate, or low conjugation capacity of the enzyme, as described previously $[5,20]$. Regarding $i N O S$, one of the most frequently investigated polymorphisms is the 
CCTTT pentanucleotide repeat $\left((\mathrm{CCTTT})_{n}\right)$ in the promotor region $[21,23]$.

The associations between asbestosis and different genetic polymorphisms have been investigated in several studies [2$8,14]$. However, to our knowledge and the available literature, the interactions between genotypes and environmental factors and between different genotypes have not been studied so far in association with asbestosis. This paper presents the influence of interactions between different genotypes (MnSOD Ala -9Val, ECSOD Arg213Gly, CAT -262C > T, GSTT1-null, GSTM1-null, GSTP1 Ile105Val, and Ala114Val and $\left.i N O S(\mathrm{CCTTT})_{n}\right)$, between genotypes and smoking, and between genotypes and cumulative asbestos exposure on the risk of developing asbestosis.

\section{Methods}

The participants in the nested case-control study were selected from a cohort of 2,080 workers occupationally exposed to asbestos who were presented at the State Board for the Recognition of Occupational Asbestos Diseases at the Clinical Institute of Occupational Medicine in Ljubljana in the period from January 1, 1998 to December 31, 2003. In this cohort, a total of 356 subjects were diagnosed with asbestosis. All these subjects were included in the present study and represented the cases. A group of 356 controls matched by gender and age with no asbestos-related disease was selected from the same cohort of workers occupationally exposed to asbestos. However, among the selected cases, 40 (11.2\%) died in the period from the recognition of the occupational disease to the time of the beginning of the study, 2 (0.6\%) developed a malignant disease and $52(14.6 \%)$ refused to participate, so the final number of cases included in the study was $262(73.6 \%)$. Among the controls, 29 (8.1\%) died, 9 (2.5\%) developed a cancer, and $53(14.9 \%)$ rejected taking part in the study, so the final number of controls was 265 (74.5\%).

The information on smoking history was collected for all subjects during an interview using a standardized questionnaire $[24,25]$. The data on the cumulative asbestos exposure, expressed in fibres $/ \mathrm{cm}^{3}$-years, were available for all the subjects from the previous study [25] as all the subjects were occupationally exposed to asbestos in the Salonit Anhovo cement manufacturing plant, Slovenia. To determine the cumulative asbestos exposure, the exposure measurements were available for all jobs. Three different methods of measurement were used: konimeter measuring particles $/ \mathrm{cm}^{3}$, a gravimetric method measuring milligrams $/ \mathrm{m}^{3}$, and membrane filter measuring fibers $/ \mathrm{cm}^{3}$. The exposure estimation included the following main steps: (1) for all production workers, work histories were obtained from the company personnel files; (2) all air measurements, information about product (asbestos or asbestos-cement) for a particular task, the process type (wet or dry), percent of time per task, units used for the air sampling measurements (particles $/ \mathrm{cm}^{3}$, milligrams $/ \mathrm{m}^{3}$, and fibres $/ \mathrm{cm}^{3}$ ), and department were entered into an ACCESS table for each production job for every year in the study period; (3) operationspecific conversion factors from particle $/ \mathrm{cm}^{3}$ to fibres $/ \mathrm{cm}^{3}$ and $\mathrm{mg} / \mathrm{m}^{3}$ to fibres $/ \mathrm{cm}^{3}$ were calculated; (4) applying the appropriate conversion factor to the measured and estimated exposure intensities, exposure intensities by job and year were calculated for asbestos for all production workers; (5) the exposure intensity table for production jobs (The Job Exposure Matrix) and the work histories for each production worker were combined using the SAS program to obtain the cumulative exposure for each worker [25].

The diagnosis of asbestosis or "no asbestos-related disease" was verified by two groups of experts of the State Board for Recognition of Occupational Asbestos Diseases, following the Helsinki Criteria for Diagnosis and Attribution of Asbestos Diseases [26] and the American Thoracic Society recommendations [27]. According to these recommendations [27], high-resolution computer tomography (HRCT) was used for the radiological diagnosis of the disease. Each group of experts consisted of an occupational physician, a radiologist, and a pulmonologist skilled in the diagnosis of asbestos-related diseases.

PCR-based methods were used for MnSOD Ala -9Val, ECSOD Arg213Gly, CAT -262C > T, GSTT1-null, GSTM1null, GSTP1 Ile105Val and Ala114Val, and $i N O S$ (CCTTT) genotyping as previously described [4-8].

The statistical analysis followed the standard procedure calculating first the descriptive statistics, $t$-test, $\chi^{2}$ test, and univariate logistic regression analysis. Next, multivariate logistic regression modelling, including genotypes, cumulative asbestos exposure, possible confounders, or effect modifiers, was employed. To test the effect modification (interactions), simple categorical models based on stratification were constructed first, followed by logistic regression models using dummy variables.

\section{Results}

The baseline characteristics (age, gender, smoking status, and cumulative asbestos exposure) of cases and controls are presented in Table 1.

The frequencies of MnSOD, ECSOD, CAT, GSTT1, GSTM1, GSTP1, and iNOS genotypes in this cohort were described previously [4-8]. In the control group, all investigated biallelic polymorphisms were in the Hardy-Weinberg equilibrium $(P>0.05$; data not shown).

Logistic regression analysis revealed no association between asbestosis and smoking (ever/never) $(\mathrm{OR}=0.98$, 95\% CI $=0.69-1.39$ ), while a significant association was observed between asbestosis and log-transformed cumulative asbestos exposure $(\mathrm{OR}=3.21,95 \% \mathrm{CI}=2.43-4.23)$. The results of univariate logistic regression analysis for $M n S O D$, ECSOD, CAT, GSTT1, GSTM1, GSTP1, and iNOS genotypes (unadjusted and adjusted by gender, age, smoking, and cumulative asbestos exposure) were reported in detail in previous studies [4-8] and are summarized in Table 2.

In a subsequent statistical analysis, no significant change in the risk of asbestosis was observed in numerous multivariate models involving different genotypes, cumulative asbestos exposure and possible confounders, or effect modifiers compared to univariate models (data not shown). 
TABLE 1: Baseline characteristics of cases and controls.

\begin{tabular}{|c|c|c|c|c|}
\hline & Cases $(n=262)$ & Controls $(n=265)$ & Test & $P$ value \\
\hline Age in years $($ mean $\pm S D)$ & $61 \pm 9.40$ & $57 \pm$ SD 9.34 & $t=5.18$ & 0.000 \\
\hline \multicolumn{5}{|l|}{ Gender } \\
\hline Male $[n(\%)]$ & $186(71)$ & $183(69)$ & & \\
\hline Female $[n(\%)]$ & $76(29)$ & $82(31)$ & $\chi^{2}=0.24$ & 0.628 \\
\hline \multicolumn{5}{|l|}{ Smoking } \\
\hline Ever/never smokers $[n]$ & $117 / 145$ & $120 / 145$ & $\chi^{2}=0.01$ & 0.919 \\
\hline Years $[$ mean $\pm \mathrm{SD}]$ & $25.92 \pm 13.37$ & $22.90 \pm 12.90$ & $t=1.77$ & 0.078 \\
\hline Pack years $[$ mean $\pm S D]$ & $21.92 \pm 15.95$ & $20.99 \pm 16.37$ & $t=0.44$ & 0.659 \\
\hline Cumulative asbestos exposure in fibres $/ \mathrm{cm}^{3}$-years $[$ mean $\pm \mathrm{SD}$ ] & $37.67 \pm 86.43$ & $11.23 \pm 23.47$ & $t=4.78$ & 0.000 \\
\hline
\end{tabular}

TABLE 2: The risk of asbestosis for MnSOD, ECSOD, CAT, GSTT1, GSTM1, GSTP1, and iNOS genotypes* .

\begin{tabular}{|c|c|c|c|c|c|}
\hline \multirow{3}{*}{ Genotype } & \multicolumn{5}{|c|}{ OR $(95 \% \mathrm{CI})$} \\
\hline & \multirow{2}{*}{ Unadjusted } & \multicolumn{4}{|c|}{ Adjusted by } \\
\hline & & Gender & Age & $\begin{array}{c}\text { Smoking } \\
\text { (ever/never) }\end{array}$ & $\begin{array}{l}\text { Cumulative } \\
\text { exposure }\end{array}$ \\
\hline $\mathrm{MnSOD}$-9Ala/Ala versus Ala/Val + Val/Val & $1.50(1.01-2.24)$ & $1.49(1.00-2.23)$ & $1.46(0.97-2.19)$ & $1.49(1.00-2.23)$ & $1.48(0.96-2.28)$ \\
\hline ECSOD Arg/Gly versus Arg/Arg & $1.63(0.62-4.27)$ & $1.61(0.61-4.22)$ & $1.49(0.56-3.96)$ & $1.65(0.63-4.32)$ & $2.07(0.72-5.94)$ \\
\hline$C A T-262 \mathrm{TT}$ versus $\mathrm{CT}+\mathrm{CC}$ & $1.36(0.70-2.62)$ & $1.34(0.70-2.60)$ & $1.31(0.67-2.57)$ & $1.37(0.71-2.66)$ & $1.91(0.93-3.91)$ \\
\hline GSTM1-null versus present & $1.01(0.71-1.43)$ & $1.00(0.70-1.42)$ & $0.94(0.66-1.35)$ & $0.99(0.70-1.41)$ & $0.97(0.67-1.42)$ \\
\hline GSTT1-null versus present & $0.61(0.40-0.94)$ & $0.62(0.40-0.94)$ & $0.63(0.40-0.97)$ & $0.63(0.41-0.97)$ & $0.60(0.38-0.96)$ \\
\hline GSTP1 105Ile/Ile versus Ile/Val + Val/Val & $1.52(1.08-2.15)$ & $1.53(0.60-1.28)$ & $1.49(1.04-2.11)$ & $1.54(1.08-2.18)$ & $1.41(0.97-2.05)$ \\
\hline GSTP1 114Ala/Ala versus Ala/Val + Val/Val & $0.97(0.64-1.48)$ & $0.97(0.64-1.48)$ & $0.99(0.65-1.53)$ & $0.94(0.62-1.44)$ & $0.86(0.55-1.36)$ \\
\hline $\begin{array}{l}\text { GSTP1 high versus intermediate + low } \\
\text { conjugation capacity }\end{array}$ & $1.49(1.06-2.10)$ & $1.50(1.06-2.11)$ & $1.45(1.03-1.07)$ & $1.50(1.06-2.13)$ & $1.36(0.94-1.98)$ \\
\hline$i N O S$ LL versus SL + SS & $1.20(0.85-1.69)$ & $1.20(0.85-1.70)$ & $1.19(0.84-1.69)$ & $1.17(0.83-1.66)$ & $1.19(0.82-1.73)$ \\
\hline
\end{tabular}

${ }^{*}$ The table summarizes the results from our previous studies.

Analysing the interactions between different genotypes, the association between MnSOD Ala -9Val polymorphism and the risk of asbestosis was modified strongly by CAT $-262 \mathrm{C}>\mathrm{T}$ polymorphism (Tables 3 and 4 ). An increased risk of asbestosis was found for the combined MnSOD -9Ala/Val and $\mathrm{Val} / \mathrm{Val}$ genotypes compared to the Ala/Ala genotype only among carriers of $C A T-262$ TT genotype $(\mathrm{OR}=2.67$, $P=0.004$ ) (Table 3). Similarly, the association between $i N O S$ $(\mathrm{CCTTT})_{n}$ polymorphism and asbestosis was modified by $C A T-262 \mathrm{C}>\mathrm{T}$ polymorphism (Tables 3 and 4 ), where a higher risk of asbestosis for the iNOS LL genotype versus the combined SL and SS genotypes was also observed only among those who had CAT $-262 \mathrm{TT}$ genotype $(\mathrm{OR}=5.14$, $P=0.000$ ) (Table 3). No interaction was found between other investigated genotypes.

Testing the interactions between different genotypes and smoking, GSTM1-null polymorphism was shown to modify the association between smoking and asbestosis (Tables 3 and 4), where an increased risk of asbestosis was found only among ever-smokers who had GSTM1-null genotype (OR = $1.48, P=0.009$ ) (Table 3 ). Similarly, the association between smoking and asbestosis was modified by iNOS (CCTTT) polymorphism (Tables 3 and 4). In this case, an elevated risk of asbestosis was detected for ever smokers with iNOS LL genotype ( $\mathrm{OR}=1.39, P=0.050)$ (Table 3 ). Other investigated genotypes showed no interaction with smoking.
To assess the interactions between the genotypes and cumulative asbestos exposure, simple categorical models that included cumulative asbestos exposure categorized as $\leq 11.23$ fibres $/ \mathrm{cm}^{3}$-years and $>11.23 \mathrm{fibres} / \mathrm{cm}^{3}$-years (11.23 fibres $/ \mathrm{cm}^{3}$-years is the mean cumulative asbestos exposure for the controls) were constructed first. The analysis showed that the association between dichotomized cumulative asbestos exposure and the risk of asbestosis was modified by $i$ NOS $(\mathrm{CCTTT})_{n}$ polymorphism (Table 3 ). The CAT -262 TT and combined CAT CT and CC genotypes showed a very different magnitude of association between the cumulative asbestos exposure and risk of asbestosis. In both cases, there was a strong risk of asbestosis, but the risk was still much higher for subjects with CAT -262 TT genotype. Next, logarithmically transformed cumulative asbestos exposure as a continuous variable was included in the logistic regression models. In these models, an important interaction was found only for the iNOS (CCTTT) ${ }_{n}$ polymorphism (Table 4), while no modifying effect was observed for other genotypes.

In all presented models, the likelihood ratio test showed that the interaction model is better if compared to the models including only the main effects $(P<0.05)$.

We also included possible confounders (age, gender, smoking, and cumulative asbestos exposure) in models testing the genotype-genotype and genotype-environmental 
TABLE 3: Stratification of MnSOD by CAT, iNOS by CAT, smoking by GSTM1, smoking by iNOS, and cumulative asbestos exposure (>11.23 versus $\leq 11.23$ ) by $i N O S$.

\begin{tabular}{|c|c|c|c|}
\hline & OR & $95 \% \mathrm{CI}$ & $P$ value \\
\hline \multicolumn{4}{|l|}{ Stratification of $M n S O D$ by $C A T$} \\
\hline Crude & 0.67 & $0.44-1.01$ & 0.047 \\
\hline$C A T-262 \mathrm{TT}$ & 2.67 & $0.57-13.07$ & \\
\hline$M n S O D-9 \mathrm{Ala} / \mathrm{Val}+\mathrm{Val} / \mathrm{Val}$ versus Ala/Ala & & & 0.004 \\
\hline $\begin{array}{l}C A T-262 \mathrm{CT}+\mathrm{CC} \\
M n S O D-9 \mathrm{Ala} / \mathrm{Val}+\mathrm{Val} / \mathrm{Val} \text { versus Ala/Ala }\end{array}$ & 0.59 & $0.38-0.93$ & \\
\hline \multicolumn{4}{|l|}{ Stratification of $i N O S$ by $C A T$} \\
\hline Crude & 1.20 & $0.85-1.69$ & 0.312 \\
\hline CAT $-262 \mathrm{TT}$ & 5.14 & $1.30-20.36$ & \\
\hline iNOS LL versus SL + SS & & & 0.000 \\
\hline $\begin{array}{l}C A T-262 \mathrm{CT}+\mathrm{CC} \\
i N O S \text { LL versus SL + SS }\end{array}$ & 1.08 & $0.75-1.55$ & \\
\hline \multicolumn{4}{|l|}{ Stratification of smoking by GSTM1 } \\
\hline Crude & 0.98 & $0.69-1.39$ & 0.357 \\
\hline GSTM1-null & 1.48 & $0.92-2.39$ & \\
\hline Smoking: ever versus never & & & 0.009 \\
\hline GSTM1-present & 0.55 & $0.31-1.00$ & \\
\hline Smoking: ever versus never & & & \\
\hline \multicolumn{4}{|l|}{ Stratification of smoking by $i N O S$} \\
\hline Crude & 0.98 & $0.69-1.39$ & 0.357 \\
\hline iNOS LL & 1.39 & $0.84-2.30$ & \\
\hline Smoking: ever versus never & & & 0.050 \\
\hline$i N O S \mathrm{SL}+\mathrm{SS}$ & 0.70 & $0.43-1.31$ & \\
\hline Smoking: ever versus never & & & \\
\hline \multicolumn{4}{|c|}{ Stratification of cumulative asbestos exposure (>11.23 versus $\leq 11.23$ ) by $i N O S$} \\
\hline Crude & 4.40 & $3.01-6.42$ & 0.000 \\
\hline iNOS LL & 3.09 & $1.81-5.25$ & \\
\hline $\begin{array}{l}\text { Cumulative exposure: }>11.23 \text { versus } \leq 11.23 \\
i N O S \text { SL + SS }\end{array}$ & & & 0.000 \\
\hline Cumulative exposure: $>11.23$ versus $\leq 11.23$ & 5.74 & $3.30-9.99$ & \\
\hline
\end{tabular}

interactions, but there was no important difference in asbestosis risk compared to the models presented (data not shown).

\section{Discussion}

The already published findings of our study show that MnSOD -9Ala/Ala and GSTP1105Ile/Ile genotypes significantly increase the risk of developing asbestosis, while a protective effect was observed for GSTT1-null genotype [4, 5 , 7]. An elevated risk of asbestosis was also observed for the ECSOD 213Arg/Gly genotype, CAT -262 TT genotype and $i N O S$ LL genotype, but the results were not significant or borderline significant [6-8]. In this paper, we additionally present the interactions between different genotypes, genotypes and smoking, and between genotypes and cumulative asbestos exposure.

A crucial finding of the current study shows that CAT $262 \mathrm{C}>\mathrm{T}$ polymorphism strongly modifies the association between MnSOD Ala -9Val polymorphism and the risk of asbestosis. As both MnSOD and CAT constitute part of the primary defence system against ROS and catalyse the sequence of reactions in the detoxification of ROS $[10,12,13]$, this interaction could be considered as biologically plausible. Similarly, the CAT -262 C > T polymorphism has been shown to also modify the association between iNOS (CCTTT) polymorphism and asbestosis. Considering that ROS and NO have been proposed to cooperate in causing the cytotoxic and mutagenic effects of asbestos fibres $[10,11]$ and based on the assumptions that NO produced by the catalytic activity of iNOS can function as a protective agent against toxic effects of $\mathrm{H}_{2} \mathrm{O}_{2}$ [28], which is detoxified by CAT [10, 12, 13], and vice versa, that $\mathrm{H}_{2} \mathrm{O}_{2}$ decreases the cytotoxicity of $\mathrm{NO}$ [29], this interaction is also a logical and important finding.

According to present knowledge, asbestosis has not been associated with smoking with certainty [30, 31]. Nevertheless, this study demonstrates a strong interaction between GSTM1null polymorphism and smoking, despite the fact that there was no independent association between either GSTM1null polymorphism or smoking and asbestosis risk. The explanation could be that both asbestos and smoking increase the production of $\operatorname{ROS}[9,32,33]$, which are known to be 
TABLE 4: Logistic regression analysis: interactions between $M n S O D$ and CAT, iNOS and CAT, GSTM1 and smoking, iNOS and smoking, and $i N O S$ and $\log$-cumulative asbestos exposure.

\begin{tabular}{|c|c|c|c|}
\hline & OR & $95 \% \mathrm{CI}$ & $P$ value \\
\hline $\begin{array}{l}M n S O D-9 \mathrm{Ala} / \mathrm{Val}+\mathrm{Val} / \mathrm{Val} \\
\text { versus Ala/Ala }\end{array}$ & 0.59 & $0.39-0.91$ & 0.016 \\
\hline$C A T-262 \mathrm{TT}$ versus $\mathrm{CT}+\mathrm{CC}$ & 0.53 & $0.17-1.62$ & 0.266 \\
\hline Interaction $^{\dagger}$ & 4.49 & $1.08-18.61$ & 0.038 \\
\hline$i N O S$ LL versus SL + SS & 1.08 & $0.75-1.55$ & 0.687 \\
\hline$C A T-262 \mathrm{TT}$ versus $\mathrm{CT}+\mathrm{CC}$ & 0.63 & $0.24-1.66$ & 0.354 \\
\hline Interaction $^{\ddagger}$ & 4.78 & $1.15-19.81$ & 0.031 \\
\hline GSTM1-null versus present & 0.63 & $0.39-1.02$ & 0.062 \\
\hline Smoking & 0.55 & $0.32-0.96$ & 0.036 \\
\hline Interaction ${ }^{\#}$ & 2.67 & $1.31-5.46$ & 0.007 \\
\hline$i N O S$ LL versus SL + SS & 0.85 & $0.53-1.37$ & 0.505 \\
\hline Smoking & 0.70 & $0.43-1.13$ & 0.143 \\
\hline Interaction $^{\S}$ & 2.00 & $0.99-4.03$ & 0.054 \\
\hline$i N O S$ LL versus SL + SS & 1.91 & $1.07-3.42$ & 0.030 \\
\hline Log cumulative exposure & 4.25 & $2.79-6.46$ & 0.000 \\
\hline Interaction $^{*}$ & 0.55 & $0.31-0.97$ & 0.037 \\
\hline
\end{tabular}

${ }^{\dagger}$ Interaction: $M n S O D-9 \mathrm{Ala} / \mathrm{Val}+\mathrm{Val} / \mathrm{Val}$ versus Ala/Ala ${ }^{*} \mathrm{CAT}-262 \mathrm{TT}$ versus $\mathrm{CT}+\mathrm{CC}$.

${ }^{*}$ Interaction: $i N O S$ LL versus SL + SS * CAT -262 TT versus CT + CC.

\# Interaction: GSTM1-null versus present ${ }^{*}$ smoking (ever/never).

${ }^{\S}$ Interaction: iNOS LL versus SL + SS * smoking (ever/never).

* Interaction: iNOS LL versus SL + SS * log cumulative exposure.

involved in the pathogenesis of asbestosis $[9,10,34,35]$. It has been suggested that cigarette smoke and asbestos increase DNA damage and ROS production in pulmonary cells synergistically $[32,33]$. Studies have shown that fresh grinding of asbestos fibres and cigarette smoke increase the production of $\mathrm{OH}^{*}$ by 2-3 times [33]. In line with these reports and considering the role of GSTM1 in the defence against ROS [14, $15,36,37]$, this result could also be physiologically explained. An interaction was also observed between smoking and iNOS $(\text { CCTTT })_{n}$ polymorphism. This interaction may be explained by the observation that cigarette smoke is the largest source of $\mathrm{NO}$ and can also increase the expression and activity of iNOS $[38,39]$ and by the suggestion that asbestos fibres may upregulate the activity of iNOS and thus the production of $\mathrm{NO}$, which is believed to be important in the initiation and progression of asbestosis [11, 17].

This study also suggested a modifying effect of iNOS $(\mathrm{CCTTT})_{n}$ polymorphism on the association between asbestosis and cumulative asbestos exposure. This has been proved in the simple categorical model and in logistic regression analysis with logarithmically transformed cumulative asbestos exposure as a continuous variable. Additional studies including more subjects are needed to elucidate whether other genetic polymorphisms modify or confound cumulative asbestos exposure-asbestosis associations.

In the present study, no bias was introduced by genetic heterogeneity because all the subjects were recruited in a small geographical area with an ethnically homogeneous population [40].

In conclusion, the findings of this study suggest that the interactions between different genotypes, genotypes and smoking, and between genotypes and asbestos exposure have an important influence on the development of asbestosis and should be seriously considered in future research on occupational/environmental asbestos-related diseases.

\section{Acknowledgments}

This research was financially supported by the Ministry of Education, Science, and Sport of the Republic of Slovenia (Grants nos. L3-9129, L3-3648, and P1-0170), was approved by the Slovenian Ethics Committee for Research in Medicine, and was carried out in line with the Helsinki Declaration.

\section{References}

[1] K. Jakobsson, A. Rannung, A. K. Alexandrie, R. Rylander, M. Albin, and L. Hagmar, "Genetic polymorphism for glutathioneS-transferase mu in asbestos cement workers," Occupational and Environmental Medicine, vol. 51, no. 12, pp. 812-816, 1994.

[2] C. M. Smith, K. T. Kelsey, J. K. Wiencke, K. Leyden, S. Levin, and D. C. Christiani, "Inherited glutathione-S-transferase deficiency is a risk factor for pulmonary asbestosis," Cancer Epidemiology Biomarkers and Prevention, vol. 3, no. 6, pp. 471-477, 1994.

[3] A. Hirvonen, S. T. Saarikoski, K. Linnainmaa et al., "Glutathione S-transferase and $\mathrm{N}$-acetyltransferase genotypes and asbestosassociated pulmonary disorders," Journal of the National Cancer Institute, vol. 88, no. 24, pp. 1853-1856, 1996.

[4] A. Franko, M. Dodič-Fikfak, N. Arnerić, and V. Dolžan, "Glutathione S-transferases GSTM1 and GSTT1 polymorphisms and asbestosis," Journal of Occupational and Environmental Medicine, vol. 49, no. 6, pp. 667-671, 2007.

[5] A. Franko, V. Dolžan, N. Arnerić, and M. Dodič-Fikfak, "The influence of genetic polymorphisms of GSTP1 on the development of asbestosis," Journal of Occupational and Environmental Medicine, vol. 50, no. 1, pp. 7-12, 2008.

[6] A. Franko, V. Dolžan, N. Arnerić, and M. Dodič-Fikfak, "Asbestosis and catalase genetic polymorphism," Arh Hig Rada Toksikol, vol. 59, no. 4, pp. 233-240, 2008.

[7] A. Franko, M. Dodič-Fikfak, N. Arnerić, and V. Dolžan, "Manganese and extracellular superoxide dismutase polymorphisms and risk for asbestosis," Journal of Biomedicine and Biotechnology, p. 493083, 2009.

[8] A. Franko, M. Dodič-Fikfak, N. Arnerić, and V. Dolžan, "Inducible nitric oxide synthase genetic polymorphism and risk of asbestosis," Journal of Biomedicine and Biotechnology, vol. 2011, Article ID 685870, 4 pages, 2011.

[9] D. W. Kamp, P. Graceffa, W. A. Pryor, and S. A. Weitzman, "The role of free radicals in asbestos-induced diseases," Free Radical Biology and Medicine, vol. 12, no. 4, pp. 293-315, 1992.

[10] V. L. Kinnula, "Oxidant and antioxidant mechanisms of lung disease caused by asbestos fibres," European Respiratory Journal, vol. 14, no. 3, pp. 706-716, 1999.

[11] V. Castranova, "Role of nitric oxide in the progression of pneumoconiosis," Biochemistry, vol. 69, no. 1, pp. 32-37, 2004.

[12] L. Forsberg, L. Lyrenäs, U. de Faire, and R. Morgenstern, "A common functional C-T substitution polymorphism in 
the promoter region of the human catalase gene influences transcription factor binding, reporter gene transcription and is correlated to blood catalase levels," Free Radical Biology and Medicine, vol. 30, no. 5, pp. 500-505, 2001.

[13] I. N. Zelko, T. J. Mariani, and R. J. Folz, "Superoxide dismutase multigene family: a comparison of the CuZn-SOD (SOD1), MnSOD (SOD2), and EC-SOD (SOD3) gene structures, evolution, and expression," Free Radical Biology and Medicine, vol. 33, no. 3, pp. 337-349, 2002.

[14] K. T. Kelsey, H. H. Nelson, J. K. Wiencke, C. M. Smith, and S. Levin, "The glutathione S-transferase theta and mu deletion polymorphisms in asbestosis," American Journal of Industrial Medicine, vol. 31, no. 3, pp. 274-279, 1997.

[15] B. Ketterer, "A bird's eye view of the glutathione transferase field," Chemico-Biological Interactions, vol. 138, no. 1, pp. 27-42, 2001.

[16] J. D. Hayes, J. U. Flanagan, and I. R. Jowsey, "Glutathione transferases," Annual Review of Pharmacology and Toxicology, vol. 45, pp. 51-88, 2005.

[17] C. C. Chao, S. H. Park, and A. E. Aust, "Participation of nitric oxide and iron in the oxidation of DNA in asbestostreated human lung epithelial cells," Archives of Biochemistry and Biophysics, vol. 326, no. 1, pp. 152-157, 1996.

[18] E. Aldieri, D. Ghigo, M. Tomatis et al., "Iron inhibits the nitric oxide synthesis elicited by asbestos in murine macrophages," Free Radical Biology and Medicine, vol. 31, no. 3, pp. 412-417, 2001.

[19] A. Hirvonen, J. Tuimala, T. Ollikainen, K. Linnainmaa, and V. Kinnula, "Manganese superoxide dismutase genotypes and asbestos-associated pulmonary disorders," Cancer Letters, vol. 178, no. 1, pp. 71-74, 2002.

[20] F. Ali-Osman, O. Akande, G. Antoun, J.-X. Mao, and J. Buolamwini, "Molecular cloning, characterization, and expression in Escherichia coli of full-length cDNAs of three human glutathione S-transferase Pi gene variants: evidence for differential catalytic activity of the encoded proteins," Journal of Biological Chemistry, vol. 272, no. 15, pp. 10004-10012, 1997.

[21] M. Tatemichi, T. Sawa, I. Gilibert, H. Tazawa, T. Katoh, and H. Ohshima, "Increased risk of intestinal type of gastric adenocarcinoma in Japanese women associated with long forms of CCTTT pentanucleotide repeat in the inducible nitric oxide synthase promoter," Cancer Letters, vol. 217, no. 2, pp. 197-202, 2005.

[22] J. Sandström, P. Nilsson, K. Karlsson, and S. L. Marklund, "10-Fold increase in human plasma extracellular superoxide dismutase content caused by a mutation in heparin-binding domain," Journal of Biological Chemistry, vol. 269, no. 29, pp. 19163-19166, 1994.

[23] W. Xu, L. Liu, P. C. Emson, C. R. Harrington, and I. G. Charles, "Evolution of a homopurine-homopyrimidine pentanucleotide repeat sequence upstream of the human inducible nitric oxide synthase gene," Gene, vol. 204, no. 1-2, pp. 165-170, 1997.

[24] B. G. Ferris, "Epidemiology standardization project (American thoracic society)," American Review of Respiratory Disease, vol. 118, no. 6, pp. 1-120, 1978.

[25] M. Dodič-Fikfak, D. Kriebel, M. M. Quinn, E. A. Eisen, and D. H. Wegman, "A case control study of lung cancer and exposure to chrysotile and amphibole at a slovenian asbestos-cement plant," Annals of Occupational Hygiene, vol. 51, no. 3, pp. 261268, 2007.
[26] A. Tossavainen, "Asbestos, asbestosis, and cancer: the Helsinki criteria for diagnosis and attribution," Scandinavian Journal of Work, Environment and Health, vol. 23, no. 4, pp. 311-316, 1997.

[27] American Thoracic Society, "Diagnosis and initial management of nonmalignant diseases related to asbestos," American Journal of Respiratory and Critical Care Medicine, vol. 170, no. 6, pp. 691751, 2004.

[28] Y. Yoshie and H. Ohshima, "Nitric oxide synergistically enhances DNA strand breakage induced by polyhydroxyaromatic compounds, but inhibits that induced by the Fenton reaction," Archives of Biochemistry and Biophysics, vol. 342, no. 1, pp. 13-21, 1997.

[29] K. Haberstroh, S. Heigold, and G. Bauer, "Transformed cellderived reactive oxygen species support and inhibit nitric oxide-mediated apoptosis induction," International Journal of Oncology, vol. 21, no. 1, pp. 145-151, 2002.

[30] E. Hnizdo and G. K. Sluis-Cremer, "Effect of tobacco smoking on the presence of asbestosis at postmortem and on the reading of irregular opacities on roentgenograms in asbestos-exposed workers," American Review of Respiratory Disease, vol. 138, no. 5, pp. 1207-1212, 1988.

[31] N. H. de Klerk, A. W. Musk, B. K. Armstrong, and M. S. Hobbs, "Smoking, exposure to crocidolite, and the incidence of lung cancer and asbestosis," British Journal of Industrial Medicine, vol. 48, no. 6, pp. 412-417, 1991.

[32] J. H. Jackson, I. U. Schraufstatter, P. A. Hyslop et al., "Role of oxidants in DNA damage: hydroxyl radical mediates the synergistic DNA damaging effects of asbestos and cigarette smoke," Journal of Clinical Investigation, vol. 80, no. 4, pp. 10901095, 1987.

[33] A. Valavanidis, T. Vlachogianni, and K. Fiotakis, "Tobacco smoke: involvement of reactive oxygen species and stable free radicals in mechanisms of oxidative damage, carcinogenesis and synergistic effects with other respirable particles," International Journal of Environmental Research and Public Health, vol. 6, no. 2, pp. 445-462, 2009.

[34] B. T. Mossman, "Mechanisms of asbestos carcinogenesis and toxicity: the amphibole hypothesis revisited," British Journal of Industrial Medicine, vol. 50, no. 8, pp. 673-676, 1993.

[35] A. Xu, H. Zhou, D. Z. Yu, and T. K. Hei, "Mechanisms of the genotoxicity of crocidolite asbestos in mammalian cells: implication from mutation patterns induced by reactive oxygen species," Environmental Health Perspectives, vol. 110, no. 10, pp. 1003-1008, 2002.

[36] S. S. Singhal, M. Saxena, H. Ahmad, S. Awasthi, A. K. Haque, and Y. C. Awasthi, "Glutathione S-transferases of human lung: characterization and evaluation of the protective role of the $\alpha$ class isozymes against lipid peroxidation," Archives of Biochemistry and Biophysics, vol. 299, no. 2, pp. 232-241, 1992.

[37] N. E. Hubbard and K. L. Erickson, "Role of 5'-lipoxygenase metabolites in the activation of peritoneal macrophages for tumoricidal function," Cellular Immunology, vol. 160, no. 1, pp. 115-122, 1995.

[38] A. van der Vliet and C. E. Cross, "Oxidants, nitrosants, and the lung," American Journal of Medicine, vol. 109, no. 5, pp. 398-421, 2000.

[39] E. Hasnis, M. Bar-Shai, Z. Burbea, and A. Z. Reznick, "Mechanisms underlying cigarette smoke-induced NF- $\kappa$ B activation in human lymphocytes: the role of reactive nitrogen species," Journal of Physiology and Pharmacology, vol. 58, no. 5, pp. 275287, 2007. 
[40] B. Vidan-Jeras, B. Jurca, V. Dolžan, M. Jeras, K. Breskvar, and M. Bohinjec, "Caucasian slovenian normal," in Human Leukocyte Antigen, D. W. Gjertson and P. I. Terasaki, Eds., pp. 180-181, American Society for Histocompatibility and Immunogenetics, Lenexa, Kan, USA, 1998. 

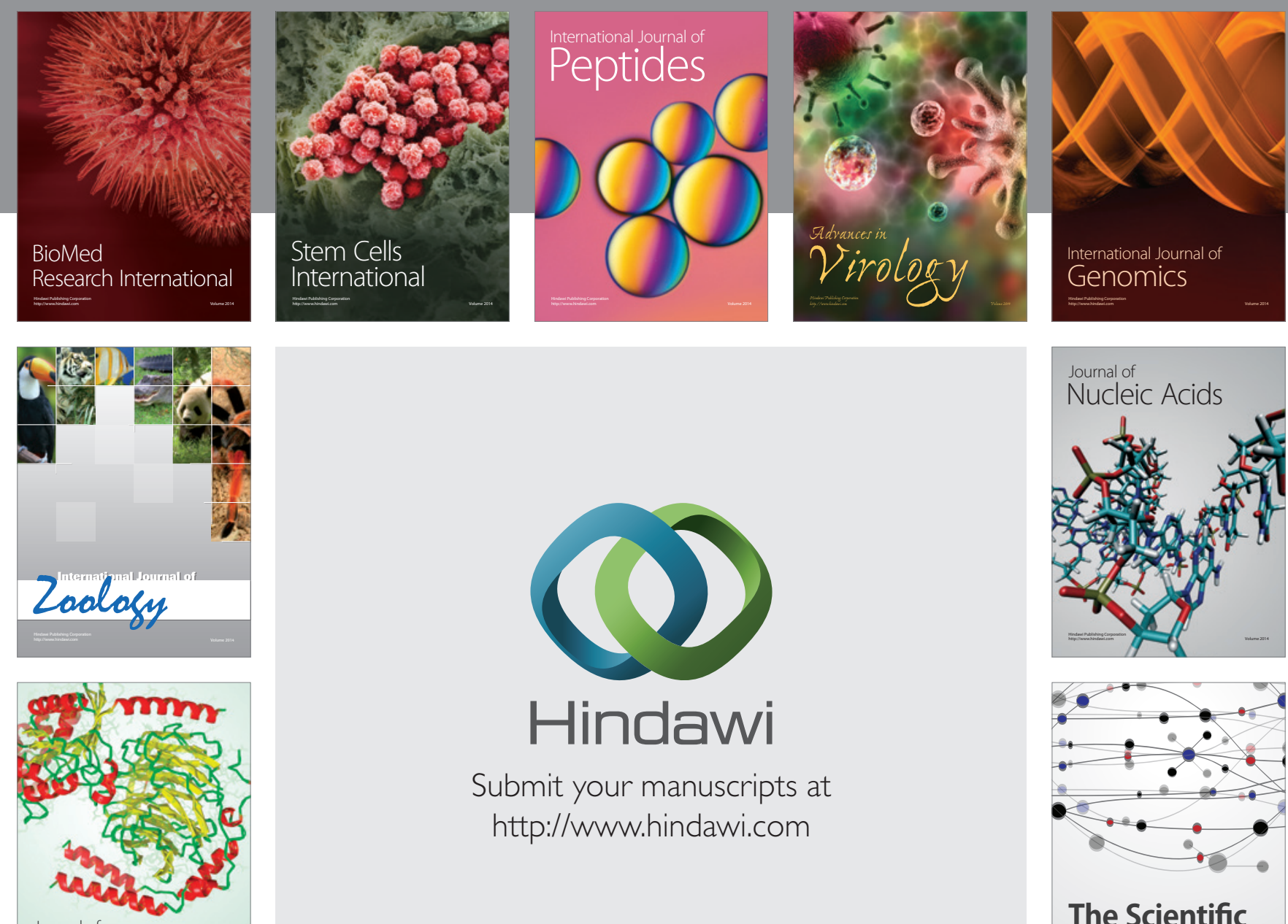

Submit your manuscripts at

http://www.hindawi.com

Journal of
Signal Transduction
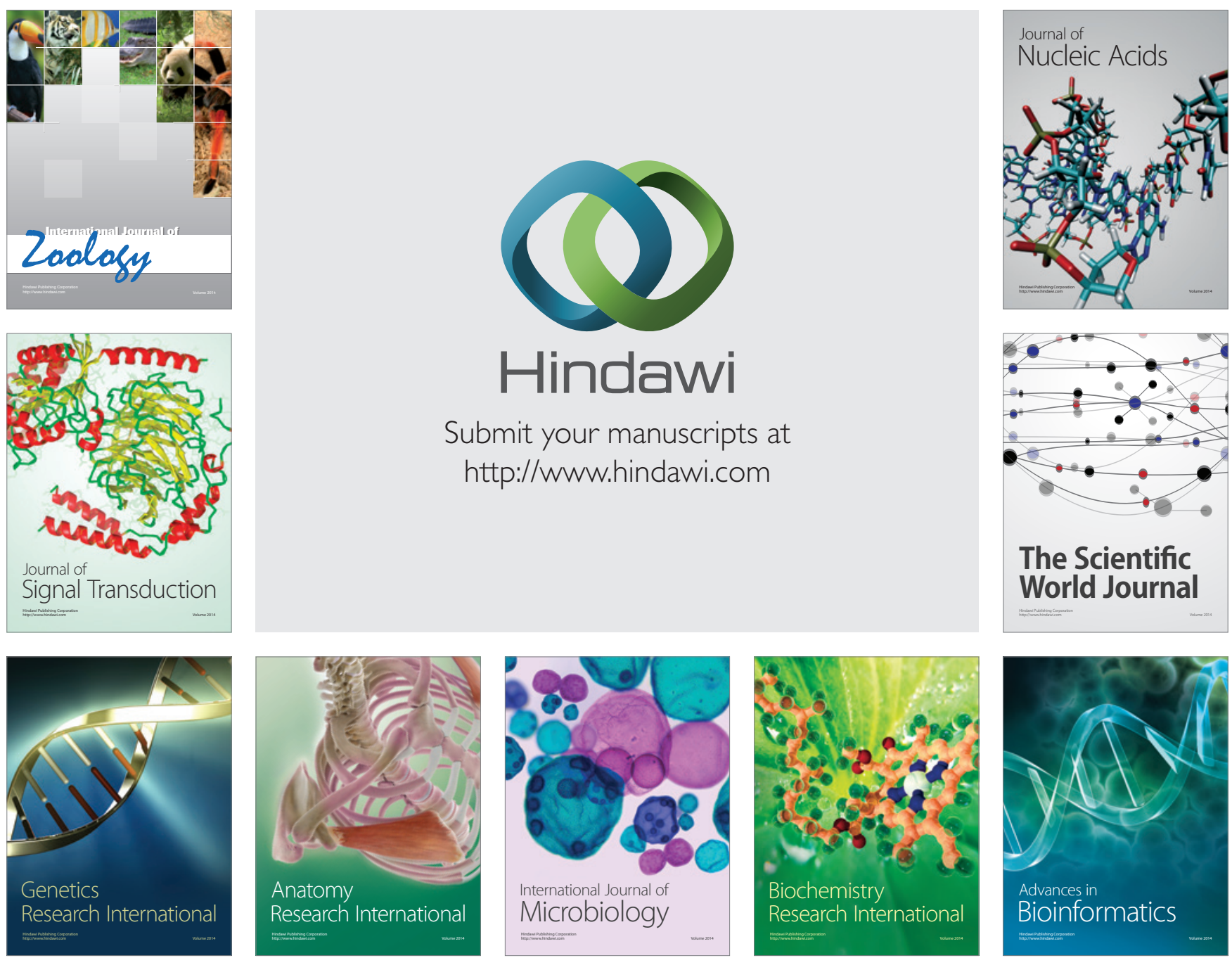

The Scientific World Journal
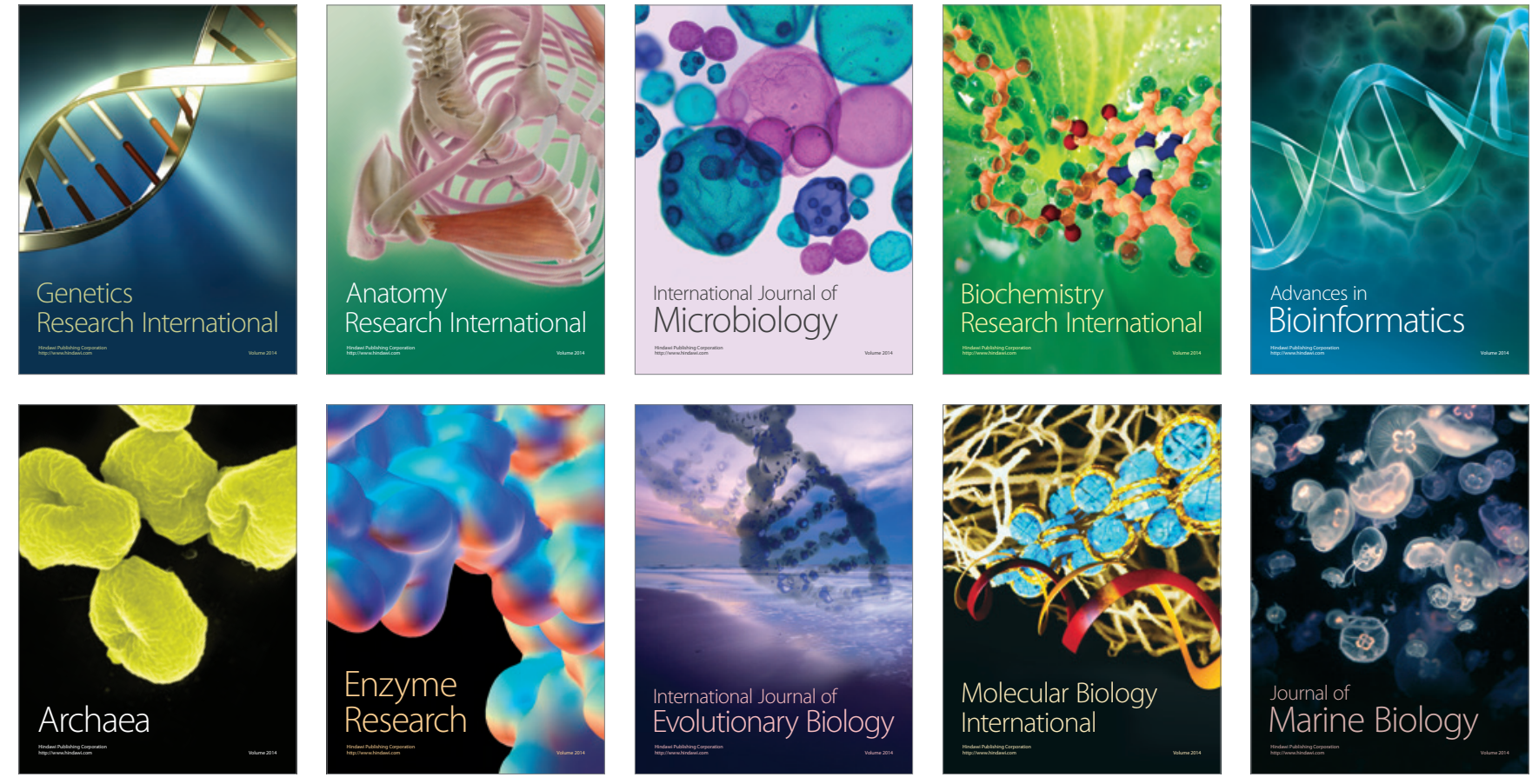